$\underline{\text { Eduardo Barrios }}$

\title{
La saturación literaria
}

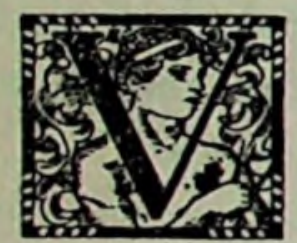

AMOS haciendo este ardoroso camino del arte con los ojos un tanto encandilados. Siempre los llevamos puestos en la ruta de compañeros y maestros, más por cierto afán de emulación y competencia que por un reflexivo espirilu de aprendizaje. Y sin embargo, tanto como la enseñanza estética y los recursos para triunfar más o menos aprisa. debería interesarnos otra lección: la que nos podría dar alguna norma con la cual conservar las venturas de la victoria y asegurarnos una felicidad literaria duradera, sin esas amarguras posadas tan de continuo, como cenizas encanecedoras, sobre las cabezas consagradas.

Porque a menudo vemos cómo los grandes ponen la planta en la gloria y explenden y subyugan un tiempo, para sentir de pronto, un día inopinado, que pasaron. que se les vuelve la espalda y se les relega cuando no cesaron de producir ni su obra revela siquiera empobrecimiento.

Lo hemos observado todos. No hace falta citar nombres o casos, lo cual excitaría estas amarguras. Todos lo vemos a diario, ¿verdad? Un escozor en nuestra conciencia de justos o un roce de melancolía nos arruga entonces el cristal del alma. y alentamos el impulso justiciero y hasta llegamos a protestar con el artículo reparador.

Pero he aqui que muy pronto sufrimos. nosotros también. la ciega inclinación al abandono del ungido. No queremos repasar sus libros ni aun nos atrae su volumen reciente. Como si aceptáramos ya que la consagración traiga tras de sí la indiferencia, dejamos decaer nuestro fervor. lo sentimos decaer sin remedio, y continuamos nuestro camino en paz, y aun, intima e inconfesadamente, nos anima un algo consolador, una emoción muy cercana al regocijo. No sabemos qué atmósfera de más fácil esperanza ha hecho más libre y despejado el campo a los que todavía vamos.

Empero, el fenómeno es triste. puede aguardarnos como un turno hostil en el porvenir por el cual luchamos. y debe sernos advertencia.

Cualquier día publicaremos un libro más, cuando precisamente nos aureolaba más gallardo y engreidor el éxito, y un critico dirá la frase terrible: . Con esta obra. que no desmerece de las anteriores, el autor no agrega sin embargo nada a su pa- 
sada producción.: O se quejará, como Ortega y Gasset de Anatole France, porque la prosa del maestro sea siempre stan cuidada, tan alerta, tan picantes; porque su técnica perfecta permanezca sla mismas: y, todavia - ioh necesidad de justificarse!porque no haya conquistado un sentimiento nuevo, cual si fuera posible al hombre el hallazgo de un nuevo sentimiento o tan sólo cambiar su punto diferencial en la vida.

Esa hora llega con demasiada frecuencia. Y no valdrá entonces la presentación de un caso. nuevo al novelista; no valdrá el cambio de tono y de metros, ritmos y rimas al poeta. Las renovaciones, a la postre, resultan disfraces, cambios de ánimo y no de individualidad. Se nos dirá. de todas maneras, algo traducible en este conceplo rotundo: „Fulano se repite.

Y habrá injusticia en esto: habrá, por lo menos, inconsecuencia: pero en el fondo habrá razón; pues por mucho que variemos los temas y las formas, siempre repetiremos la personalidad.

El daño, entonces, ¿nos lo hacemos nosotros mismos? Yo creo que sí. Nos lo hacemos nosotros mismos causando una saturación del público sensible. inteligente. asimilador y entusiasta, cabalmente aquel que juzga y propaga.

Veámoslo.

Aparece un gran artista... Quiero concretarme a los grandes, para reducir el ensayo, y porque entre los extremos todo punto intermedio queda comprendido... Aparece, digo, un gran artista, y cautiva. Todos se dan a devorar cuanto publica. Su obra nos sacude, nos deslumbra, nos apasiona. La divulgamos asombrados en la charla, en el artículo. en la entrevista, en la conferencia. Empresarios, editores y periódicos se disputan su voz y su palabra fascinadoras. Se citan sus pensamientos; no se puede prescindir de él y se empieza a vivir con la propia sensibilidad realmente modificada por el sentir de aquel temperamento; concluye por formarse a veces en la sociedad todo un ambiente renovado: y cun día entre los días.. sin advertirlo, todos nos hemos asimilado, cuál más. cuál menos, al ser extraordinario. Hemos incorporado a nuestras almas su alma, su lógica a nuestra lógica. los esquemas por donde discurre su pensamiento a la mecánica del nuestro; sus puntos de vista y las actitudes originales de su espíritu frente a las cosas de la vida vienen a sernos habituales, a pertenecernos también. Y ese hombre excepcional parece haber concluido de serlo. Su obra nos ha saturado y en lo futuro no conseguirá darnos el elemento primordial de seducción: la sorpresa. Cuanto nos pueda contar. lo esperamos, casi lo sabemos de antemano: quién sabe si muchos pasos vistos o vividos nos lo sugirieron ya. Ese hombre, pues, ya no nos interesa mucho. pasó, es viejo.

Nos señalará ese artista en adelante aspectos que quizás no habia señalado. explotará temas que nunca explotó. No parecerán nuevos a nadie. Exhibido por esa mano. ningún singular ejemplo, ningún raro matiz reteñirán con energía bastante los espíritus, mucho menos conseguirán encenderlos.

$Y$ él se tiene que sorprender con dolor cuando alguien. con el desgano de una mueca, escriba: . Con esta obra, que no desmerece de las anteriores, el au- 
tor no agrega sin embargo nada a su pasada producción.. O simplemente: .Fulano se repites. Porque él puede probar que no repitió un sólo pensamiento. una sola emoción, una sola sensación, una sola imagen; y es verdad. Pero... la personalidad se repite, y eso basta.

Ahora, ¿quién tiene la culpa de este abandono envenenador de tantas vidas gloriosas? ¿El artista, consciente de estar hablando de lo que jamás trató? ¿El público, sabedor por presentimiento de cuanto puede aquella pluma enviarle ya? Lo hemos anotado: sólo la saturación. Consumada ella, no veremos ya en el nuevo libro del abandonado ciertos valores inéditos. o los distinguiremos apenas. oscura y flojamente, a través de una enervante bruma levantada por la saluración en nuestra atmósfera interna.

Este daño, por suerte, no se lo hace para siempre el escritor que satura. Aun la intoxicación pasa. La obra deja en el ambiente el zumo perdurable, abono con que la raza madura gracias a sus ascendientes selectos. La justicia se equilibra al fin. la posteridad paga, devuelve. Sólo que esto ocurre cuando sel extraordinario, murió desencantado o se mantuvo preterido muchos años. $Y$ en ello está cabalmente el drama, en esa gloria aventada, en el secuestro de esa dicha que una vez embriagó, en la esponja de hiel y vinagre estrujada sobre una vejez egregia y sola tras de tanla corte y tanta compañia.

No marchemos con los ojos puestos en la ruta de compañeros y maestros tan sólo por afán de emulación y competencia o tras la enseñanza estética y los medios para triunfar más o menos aprisa. Aprovechemos la advertencia. No saturemos.

Aunque hay casos en los cuales una personalidad muy original, muy diferenciada, poderosa y penetrante hace la saturación violenta y acaso inevitable. he podido yo discernir que el pecado de los grandes artistas de perdido favor y felicidad rota consiste, excepto algunos ejemplos de decadencia por vanidad o agotamiento. en haber sido ellos muy fecundos y no haber graduado las entregas de su personalidad. Ante el monstruo cariñoso, entusiasta y aclamador, pero de asimilación pronta y tedio fácil. ha de emplearse la prudencia, y aun la maña. y la malicia. Por la defensa del mañana, por no malograr esa dicha tras la cual vamos hoy, midamos el paso. sopesemos la colaboración en los periódicos, calculemos avaros las dosis que de nuestras almas vayamos esparciendo a los vientos de los hombres.

Siempre resultará preferible ser echado de menos y que. si alguno quedō hechizado por un libro nuestro, nos anhele mucho tiempo la nueva palabra y se lamente y suspire ante nuestro callar. No dure nuestra vida más allá de nuesíra gloria. Rehuyamos la consagración veloz. Consagración, ya lo sabemos, suele llamar el público analista y dirigente a su manera de cancelar con nosotros. Aun cuando fanatizamos al lector, el enemigo ssaturación, socava escondido y sigiloso. Ay de aquel a quien se le llegue a presentir qué le resta por decir en lo futurol El crítico capaz de usar su juicio como instrumento de precisión y de juzgarnos dentro del tiempo las realizaciones y las posibilidades no siempre recuerda con oportunidad esta .cuarta dimensión.. Es, además, un hombre de 
talento; y no se equivocaria tal vez quien dijera: el talento se mide por la capacidad de aburrirse.

Un amigo novelista me ponía en una carta frenética: Usted en su tierra y yo en la mía. tenemos que lanzar muchas novelas, compañero. Otro me hablaba asi: . Conviene que nuestra firma esté siempre bajo los ojos del público. Es olvidadizo y nos deja por los más trabajadores.. Aparte de que trabajar mucho no significa mucho prodigarse. prefiero que la saturación de mis lectores se cumpla un poco después de extinguidos mis días sobre la tierra.

No esperemos una suerte excepcional. No la espere tampoco el genio. Antes bien, al genio de la obra, añádase el genio de la dosificación. El público, como inferior al genio, es vaso por lo mismo fácil de colmar y desbordar por él.

Yo, tan distante del genio, en cada ocasión que alguien me dice: QQuiero buscar todas sus obras,. deseo fervientemente: ¡iOjalá sólo encuentre una o dos!. y tras de mucho ansiarlas. tras de una prolongada distracción de su espíritu por escritores diversos,. Disfruto asi, además, de otro beneficio: la alegria ante la buena obra de mis compañeros. Ellos, triunfando. llenan los espacios en que debo dejar al público descansar de mí y yo, en retorno, recibo con amor sus éxitos y me ennoblezco deseando a muchos el triunfo.

Dura demasiado la vida del hombre si se mide por el cansancio de quien recibe sus libros. Cuántas veces, al morir un gran poeta, se ha dicho en su elogio: .Hasta supo morirse a tiempo!s

$Y$ otros nombres afluirán a vuestra mente ahora-os estoy leyendo el pensamiento-engarzados en este cálculo: Si se muriesen hoy. saldrian ganando. se salvarian de la saturación. que ya para ellos empezó y avanza.

Hay todavía la saluración de si mismo. La eterna queja de ejel dolor de pensar! s no es sino una forma de autosaturación. Nuestra tendencia espiritual, el conjunto de nuestras inquietudes peculiares, el procedimiento acostumbrado en nuestro propio discurso nos impregnan, nos hastian. nos pesan como el pecado original. Constituyen nuestra personalidad, que ha de repetirsenos por fuerza más que otra alguna. Precisa hallarse muy vendado por el orgullo para no cansarse en cierta hora de sí mismo. ¿Nunca os llenó de tedio insufrible vuestra voz escuchada de repente en la conversación?

Sí; el fruto del árbol de la ciencia ejerce su maldición dentro del yo. sólo alli se trueca en el dolor de pensar y saber. Si lo buscamos allá adonde no va nuestro pensamiento, si lo miramos en una máquina moderna. por ejemplo. en la prensa casi pensante del periódico, nos subyuga por asombro. Ya no es ponzoña maldita de la Serpiente: es don bendecido de Dios.

Todas estas novedades estridentes del arte ultraista acaso hayan nacido del exceso de producción realizado en nuestra época.

La fecundidad sin cautela, creámoslo. deja de significar virtud desde el momento en que a unos lleva al hastio y a otros al dolor de sentirse preteridos. No hagan caso los niños al papagayo profesor de literatura. que saca su eterno ejemplo de aquel gran majadero cuyas obras en menos de horas veinticuatro pasaron de las musas al teatro. Sólo somos, a la postre, el autor de uno o 
dos libros. A Lope no le debemos sino .Fuente Ovejunas. Y la mucha fecundidad representará un valor-y relativo-en vuestro provecho, acaso únicamente después de vuestra muerte, cuando os juzguen sin el temor de que volváis a hablar...

Bien; paradojas aparte, no escribamos sino cuando realmente tengamos algo que decir, y. además, cuidemos de llevar nuestra producción al público más bien alargando el camino, como alarga el buen amador el placer de su doncella. Llegar a los sesenta con una gloria mustia y caducada, equivale a andar con nuestro cadáver a cuestas.

$Y$ cuando resuene en nuestros oidos el alerta de que la fecundidad incauta y prodigada con vehemencia tiene triste el mañana, no nos empecinemos en buscar un acomodaticio y consolador mentís. Nos encariñamos con la producción numerosa, una lista nutrida de libros bajo nuestro nombre nos halaga, seduce y engrie; mas todo ello es traición del sentimiento. Hace falta siempre un poco de dureza cerebral sobre las blanduras del corazón. ¿Acaso la realización de nuestro arte no nos ha enseñado que se da elícacia al sentimiento aliándolo con un poco de cerebro, tal como en la buena moneda se ha de mezclar un metal duro al oro fino?

El corazón sin disciplina nos pierde, se destroza con sus propias fuerzas. $Y$ estas fuerzas-no lo olvidemos-se saben colocar en segundo término para gobernar a su sabor el juego. Disimulándose, operan sobre la imaginación. la conducen al logro de razonamientos gratos. Pero debemos relacionar los actos con sus móviles genuinos, ponerlos frente a sus causas originales y medir sus consecuencias difinitivas.

Así andaremos seguros y andaremos lejos, fecundos pero felices.

$Y$ hay tiempo para todo, nos recordó Dario:

-Ya nos lo dijo el Eclesiastés:

tiempo hay de todo: hay tiempo de amar.

tiempo de ganar, tiempo de perder.

tiempo de plantar, tiempo de coger.

tiempo de llorar. tiempo de reír.

tiempo de rasgar, tiempo de coser.

tiempo de esparcir y de recoger.

tiempo de nacer, tiempo de morirs.

EDUARDO BARRIOS.

Santiago de Chile. Junio de 1923. 